the EPAA sits between industry and the public, and is linked with industry and the regulators, it should be an ideal body to act as an "honest broker".

For the coming generation of scientists that link with the regulators could be crucial. Nynke Kramer from the Institute for Risk Assessment Sciences, the Netherlands, spoke up for that generation: "As young scientists we don't really know what regulators want. We know what we can do, but it would be really nice if the EPAA comes in as a broker - but it must be a proactive broker," she said.

If the conference had a leitmotif - apart from dissemination - it would be the well-known question of relations with regulators: what do they want, how can others talk to them, how can they be convinced to take up new ideas? How weak can a dataset be before the regulatory authorities reject it?

However, it's not all one-sided. Craig's surveys for the EPAA by The Centre looked at a mix of regulators. The story they told was that they go looking for the information - in journals, for example - but that in general "only industry" ever sends information in to them.

Engagement with regulators will be achieved by "an intricate learning" process, said Simon Webb from Procter \& Gamble. It is all the more necessary, he thought, since regulators are always going to want freedom to consider things on a case- by-case basis. Uncertainty about what regulators want is "not a dissemination problem, but a relationship one", he said.

\section{Conclusions of the workshop}

The first conclusion to be distilled from the discussion is that the workshop agreed, in Botham's words, "that it is worth trying to excite the EPAA and others in the idea of the EPAA providing an honest broker service, which we would call a marketplace."

The second conclusion is that progress will only come by doing something concrete, even if small. Botham called for "smallscale experiments, a few things next year", where the EPAA can test the water and see how well the experiments have gone.

Thirdly, dialogue with regulators must continue, in various forms. "We should ask them not just what information they want pushed to them, but also ask, in confidence, what they see as their information gaps."

The full report of the workshop is available on the EPAA website (www.epaa.eu.com).

\section{Correspondence to}

Cornelis Brekelmans

Adviser

European Commission

Directorate General for Enterprise and Industry

e-mail: entr-epaa@ec.europa.eu

\title{
Animal suffering and distress - what are the limits of ethical defensibility?
}

\author{
Bad Boll, Germany, $5^{\text {th }}-7^{\text {th }}$ March 2010
}

The introductory lecture at the Protestant Academy Bad Boll by Peter Kunzmann, professor of ethics in Jena, dealt with the difference between our treatment of animals held as pets or for experimental purposes, e.g. rabbits. The fact that this ambivalence is gaining recognition and has elicited protest is the consequence of an improvement in ethical valued put on animals by society. Associated contradictions may be found both in the Austrian and German Animal Protection Laws. In the lecturer's opinion, this ambivalence follows from different types of animal-human relationships and may differ between cultures. Kunzmann criticised the categorisation of animals into higher and lower orders and the related special status of primates. He suggested that animal protection should be approached from the animal's perspective and that the problem lies less in unfair but rather in inadequate treatment, e.g. the instrumentalisation of animals.

The Swiss jurist Gieri Bolliger from the Stiftung für das Tier im Recht showed, using dehorning of cattle as an exam- ple, how ethical defensibility must be determined according to $\S 1$ of the German Animal Protection Law. The procedure must be justified and commensurability must be demonstrated. The Law requires in some but not all areas that expected benefits must outweigh distress caused. Commensurability requires that the procedure must be adequate and necessary to reach the legitimate purpose. In the example, although dehorning is adequate to reduce the risk of injury for animal and handler, this goal may also be reached by changing the stable design. This result argues against dehorning on ethical grounds although it is still commonly practiced.

Thomas Richter, ethologist at Nürtingen-Geislingen University, discussed whether animal welfare can be evaluated using animal welfare indices. In his opinion, animal welfare depends on a positive mental state of the animal. Neither animal welfare indices referring to the animal's housing, nor the relationship between the handler and the animal or physiological parameters, such as heart rate and stereotypy, are suitable 
to assess the animal's mental state. Based on this, allowing an animal to choose between different options is a laborious but exact method to ensure animal welfare.

Brigitte Rusche, Akademie für Tierschutz in Neubiberg, explained the general legal constraints and the approach to conflicts of interest regarding animal experiments. German Basic Law ( $\$ 90 \mathrm{BGB}$ ) recognises the value of animals since 1990. However, the clause requiring justification for subjecting animals to pain and distress is too general and must be defined. It should be considered whether bans on performing animal experiments for certain aims should be extended, e.g. to include experiments on vertebrates or severe experiments. It should further be questioned whether the instruments for the ethical evaluation of animal experiments are effective. The different requirements set on killing animals allows them to be subjected to distress for different reasons. Housing conditions are only specified in by-laws for some animals. On the other hand, handling animals requires a permit in some areas, e.g. circuses or animal shelters. It is unclear whether these few concrete prohibitions and unspecific general requirements still reflect the social consensus.

Next to the animal protection check-up (Tierschutz-TÜV) mentioned in the Animal Protection Law, an animal husbandry check-up, an animal protection lawyer, an animal ombudsman (like in Austria) or a federal animal protection agent (like in the Federal State of Hessen) and a collective action were proposed.

Four work groups discussed distress caused to animals kept and handled as pets, livestock, wild animals in human care and experimental animals, asking what is ethically defensible and which measures can be taken to ensure ethical treatment of the animals. The results were presented and discussed in a final plenary session. These shall be condensed as a Bad Boll Appeal.

The group on experimental animals reached the consensus that severe animal experiments in education and in basic research should be banned. An animal's ability to suffer was considered a useful basis to decide which species may be used for experiments. No agreement was reached on whether and which species should be excluded from use as experimental animals. It was suggested that ethical evaluation should be based on quantification of the experimental goals with regard to applicability and probability of success, coupled to a time horizon. A retrospective analysis of animal experiments should be submitted to allow a cost-benefit analysis.

It should be ensured that persons and instruments involved in the authorisation procedure have sufficient time to deal with the numerous and lengthy applications. More personnel with suitable qualifications, a catalogue of criteria for the ethical assessment and external consultation are necessary. The Animal Protection Law should require that the animal welfare officer is independent, engaged full-time in this capacity and able to lodge complaints. The $\$ 15$-commission, of which the animal welfare officer should be a member, must be independent; this would be promoted by an animal protection ombudsman.
It was further discussed how the ethical defensibility can be determined and whether animal experiments for luxury items or self-inflicted health problems, such as smoking, should be banned. It was agreed that regulatory animal experiments should at least be subject to a modified authorisation procedure evaluating their necessity. Breeding and killing of animals are not subject to sufficient regulations to allow the evaluation of ethical defensibility. The work group's results were affirmed by the audience.

A resolution on voting on the EU Directive for the protection of animals used for experimental and other scientific purposes was proposed by Christoph Maisack. This demands that the Federal Government ensures that the following improvements, which were already part of the proposal for the revision of the Directive published on $5^{\text {th }}$ November 2008 by the European Commission, are indeed included in the revised Directive: provision on authorisation of all procedures involving live vertebrates, cephalopods or decapods; ethical evaluation by the competent authority as an essential requirement for authorisation; obligatory consultation of independent third parties in the evaluation; no experiments on live animals as soon as scientifically satisfactory alternative methods are available; expedited acceptance and approval procedure for alternative methods for regulatory testing; invariable ban on procedures involving severe pain, distress and suffering anticipated to be of longer duration; unconditional enforcement of the housing and care requirements stipulated in Annex A; obligatory admission procedures for all persons wanting to take part in procedures on live vertebrates, cephalopods or decapods; stipulation that at least half of the official controls in institutions breeding, distributing and using animals be unannounced; it is considered especially important that a special article - pursuant to the subsidiarity principle (Art. 5 of the EU treaty) and the proposal made by the European Parliament on $4^{\text {th }}$ and $5^{\text {th }}$ May 2009 - clearly states that the Member States are not prevented from passing and implementing stricter regulations to improve animal welfare and protect animals used for scientific purposes even after the Directive enters into force. The resolution gained a very broad support of the audience.

The meeting initiated varied fruitful discussions, although it was often difficult to find a consensus. Despite the aim of the meeting being to determine the limits of suffering caused to animals that can be ethically defensible, a number of participants held the view that animals may under no circumstances be subjected to suffering. It was suggested that the next meeting be held on the animal's dignity.

Silke Bitz

Menschen für Tierrechte.

Tierversuchsgegner Baden-Württemberg e.V. www.tierrechte-bw.de 